\title{
Olympic diabetes
}

lan W Gallen, Ann Redgrave and Steven Redgrave

\begin{abstract}
Winning an Olympic gold medal represents the pinnacle of achievement in any sporting event, to do so with diabetes is almost miraculous. This report outlines the history and management of Steven Redgrave's diabetes, and describes the physiology associated with the extremes of human endurance and the difficulties that this presents.
\end{abstract}

KEY WORDS: diabetes type 1, diabetes type 2, exercise, exercise physiology, glucose metabolism, glucose storage, insulin lispon, rowing

\section{Case report}

Steven Redgrave, then 35 years old, presented in September 1997 with a classical history of diabetes: a short history of insatiable thirst, marked polyuria, a weight loss (ca 2-3 kg) and a marked loss of athletic performance. His general practitioner promptly diagnosed diabetes and referred him to the Chiltern Diabetes Centre. He was an internationally competitive oarsman with an outstanding sporting career who had won gold medals at each of the previous four Olympic Games.

At presentation, he gave a past medical history of intermittent ulcerative colitis diagnosed in 1992, which was then under good control, and of appendicectomy in April 1997. He had required insulin (20-30 units per day) for prednisolone-induced diabetes during treatment for previous exacerbation of colitis. He weighed $105 \mathrm{~kg}$ and on examination was a very fit man. He had no diabetic complications (specifically no evidence of peripheral vascular disease) and normal peripheral sensation, power, tone and reflexes. The random blood glucose was $25 \mathrm{mmol} / \mathrm{l}$ associated with moderate ketonuria, but no proteinuria. The results of investigation suggested a diagnosis of type 2 diabetes with a negative islet cell antibody titre and detectable C-peptide.

He was treated with subcutaneous insulin (Insulatard) twice daily. Once stable, he was transferred to an intensified insulin regimen with multiple daily injections of Lispro insulin and Isophane insulin before bed. After the first month on this regimen, significant problems were encountered. Steven struggled with severe hypoglycaemia after rowing, and noted low levels of energy with reduced stamina and excessively fast heart rates during training.
Analysis suggested excessive Isophane insulin action. Evening Isophane insulin was reduced, but daytime analogue injections were increased. The insulin regimen at this time is shown in Table 1 . His blood sugar control during this period was excellent (4-10 mmol throughout the day). His glycosylated haemoglobin was $7.4 \%$.

Over the next year his diabetes was managed with 6-8 units of Lispro insulin four times a day. There was a steady improvement in his athletic performance, with his crew winning the 1998 World Rowing Championships. As usually happens following initiation of insulin therapy, the dose had to be increased substantially. During winter training in 1999, Steven again noticed marked loss of performance after 2-3 minutes of exercise, with a rapid heart rate. No obvious cause for his loss of stamina was found. Other hormonal disorders and an exacerbation of his colitis were excluded.

A review with his coach, physiologist, dietitian and physician concluded that the carbohydrate intake was probably insufficient to support the level of exercise required. The food intake was substantially increased and the insulin dose increased to 12 units of Isophane insulin twice daily and 5-6 injections of Lispro insulin (2-16 units with each meal). With these changes, Steven's physical endurance markedly improved and the crew won both the Henley Royal Regatta and the World Rowing Championships in 1999.

In the run up to the 2000 Sydney Olympics, Steven's performance seemed to be back to prediagnosis levels, and the team easily won the Henley Royal Regatta. However, some eight weeks before the start date Steven noticed a recurrence of loss of power after five minutes of maximum exercise.

Table 1. Steven Redgrave's revised insulin regimen.

\begin{tabular}{lll}
\hline Time & Activity & Dose \\
\hline $7.0 \mathrm{am}$ & $\begin{array}{l}\text { Before training } \\
\text { With breakfast }\end{array}$ & 2 units Lispro insulin \\
& After training & 8 units Lispro insulin \\
$11.15 \mathrm{am}$ & 8 units Isophane insulin \\
Afternoon & Meal & 8 units Lispro insulin \\
& & 10 units Isophane insulin \\
Before bed & Supper & 5 units Lispro insulin \\
& & 4 units Isophane insulin
\end{tabular}


Again, blood sugar control was excellent, and the cause of this loss of performance was not obvious. The help of the Muscle Metabolism Laboratory at Queen's Medical Centre, Nottingham, was sought. Studies were undertaken there of cardiovascular, respiratory, blood glucose and catecholamine responses, and fuel utilisation during graded exercise, with glucose disposal using the hyperinsulinaemic glucose clamp technique. These studies demonstrated that Steven's muscle metabolism during exercise was not altered in the presence of diabetes, but his ability to store glycogen was reduced. This explained his problems with extended exercise. This information was used to adjust both food intake and insulin dosage: approximately $120 \mathrm{~g}$ of glucose was taken, with additional doses of Lispro insulin during early rest periods after exercise to maximise the amount of glycogen deposition.

Steven and the team went to altitude training camp before travelling to Australia, from where there was daily contact to adjust insulin dosage and ensure normoglycaemia. Food ingestion and insulin dose strategies were rehearsed to deal with variation in race start time or several races in close succession. In September 2000, Steven and his three colleagues won the Gold in the Coxless Four Rowing event at the Sydney Olympic Games.

\section{Discussion}

\section{Insulin and diet}

As for any person, the diagnosis of diabetes was a shock and disappointment for Steven. His immediate response was that his sporting career would be at an end. Over the first few days, there were intense discussions with Steven, his wife (coincidentally,

\section{Key Points}

\section{Diabetes mellitus impacts on the physiological response to exercise, particularly with imbalance between glucose utilisation and production, and the mobilisation of other fuel sources \\ Maintenance of good glycaemic control, and avoidance of hypoglycaemia during and following exercise are difficult with insulin therapy}

Causes of impaired physical performance, even when glycaemic control appears satisfactory may not be obvious

Careful attention must be taken with appropriate feeding and insulin therapy regimes

Multiple insulin injections using short acting analogue insulin are usually necessary

With carefully planned, practised and administered treatment strategies, physical performance can return to the prediagnosis level or to that of non-diabetic athletes

Diabetic athletes should be encouraged to follow their ambitions, to reach for their highest achievable performance the team physician) and his coach, Jürgen Groebler, to decide whether it was practical to manage his diabetes and continue the arduous training schedule necessary to win an Olympic gold medal. Competitive rowing is one of the most strenuous endurance events, requiring sustained maximum power output. A typical training day would include a $12 \mathrm{~km}$ run, followed by 90 minutes rowing and a further period in the gym using weights and the rowing ergometer. The race event is usually 6-10 minutes of intense exercise at greater that $80 \%$ maximum oxygen consumption.

Some potential major problems were immediately apparent:

1 Prolonged periods of training and competitive rowing were likely to produce marked changes in glucose utilisation, with consequent swings in blood glucose control.

2 The prediabetes diagnosis diet contained approximately 7,000 cal per day, mainly foods with a high glycaemic index, likely to produce wide swings in blood glucose.

It was apparent at the outset that for Steven to achieve a further gold medal, the traditional model of diabetes care, namely the achievement of normoglycaemia, would not be enough. The aim would have to be to restore Steven's performance to the previous outstanding level, and thus remove diabetes as an impediment. The task was daunting because there were no precedents to follow. The particular concern was to avoid hypoglycaemia during river training. Early experience following the introduction of Lispro insulin (an analogue insulin) suggested that this problem might be manageable. ${ }^{1}$ Conventional human soluble insulin (Actrapid, Humulin S) has a relatively slow onset of action, peaking at approximately two hours after subcutaneous injection, with a relatively prolonged tail of action (6-8 hours). By contrast, Lispro insulin reaches its peak action within an hour of injection, with a total duration of action of approximately three hours. ${ }^{2,3}$ The use of a continuous subcutaneous insulin infusion pump was considered because it enables infusion rates to be adjusted rapidly to meet requirements. This seemed to offer potentially near-physiological insulin replacement, ${ }^{4,5}$ but the reported experience of such pump therapy in exercise was limited and Steven felt that the pump would be cumbersome, particularly during rowing.

\section{Management plan}

A management plan was developed using quick-acting analogue insulin with ingestion of high carbohydrate-containing meals and relatively small quantities of Humulin I (Isophane insulin) overnight. The principle underlying management was essentially similar to that for other people with diabetes treated with insulin, with the dose of insulin titrated against the other variables of food ingestion and exercise. Frequent blood glucose monitoring (up to 10 times daily) was carried out. The type, intensity and duration of exercise were charted and detailed food diaries recorded. Steven did the day-to-day monitoring and adjustment of insulin himself, referring to the Diabetes Centre for advice when needed and for review of his blood glucose profiles alongside his training schedules/food intake. The primary 
concern of these reviews was to promote near normoglycaemia, but further important factors were objective assessment of athletic performance and the differences between the day-to-day management of his diabetes during training, rest and competition days. Perhaps uniquely, there were detailed prediagnosis data on maximum power output, stamina, gaseous exchange, cardiovascular function and lactate tolerance.

\section{Physiological responses}

Both training and competition are a significant physiological challenge, with massively increased oxygen and fuel demands. These needs are met through a synchronised cardiovascular and endocrine response. The increased oxygen demand of muscle is met by increased cardiac output and respiratory effort. Maximum oxygen consumption, carbon dioxide output, ventilatory capacity and cardiac output are normal in uncomplicated diabetes. ${ }^{6,7}$ However, the endocrine response and mobilisation of other fuels from remote body stores are altered in diabetes.

With the onset of exercise, muscle contraction leads to an immediate fall in intracellular adenosine triphosphate levels, the only fuel available for contractile function. ${ }^{8}$ High-energy phosphate levels are replenished initially from intracellular phosphocreatine stores, which are very limited and must be replaced by the muscle mitochondria. ${ }^{9}$ Intramuscular glycogen is then immediately mobilised and is the major fuel source during early exercise. ${ }^{10,11}$ As energy demands continue, glucose is taken up into muscle from the bloodstream. In health, blood glucose concentration is kept within a narrow range during exercise, with muscle glucose utilisation closely balanced by hepatic and renal gluconeogenesis. The stimulation of gluconeogenesis, induced by exercise and falling blood glucose, is mediated by rapidly increasing levels of glucagon, ${ }^{12-14}$ the catecholamines ${ }^{15-17}$ and growth hormone. ${ }^{18}$ Low levels of insulin, controlling hepatic glucose output, regulate glucose production. ${ }^{19}$ As the exercise continues, and the levels of counter-regulatory hormones increase, other fuel sources become available: ${ }^{20}$ triglycerides are mobilised from fat stores, and the non-esterified free fatty acids released can be used directly by muscle and are also converted into ketone bodies by the liver. These can also be oxidised by muscle. If the partial pressure of oxygen in the skeletal muscle remains sufficiently high, these become the preferred fuel source. $^{21}$

When muscles become relatively hypoxic, they cannot oxidise glucose, non-esterified free fatty acids or ketones, and anaerobic metabolism of glucose then becomes more important. In this situation, muscles produce more lactate than can be taken up and metabolised by the liver, and exercise must be limited by the build-up of lactic acid. Physical training increases the capacity for oxygen delivery through improved lung function and cardiac output, and raises the tolerance to high lactate concentration. During competition, because of the anaerobic state, glucose is the principal fuel. Thus, the key limitations to maximum performance are the:

- ability for the cardiovascular system to provide oxygen to the tissues

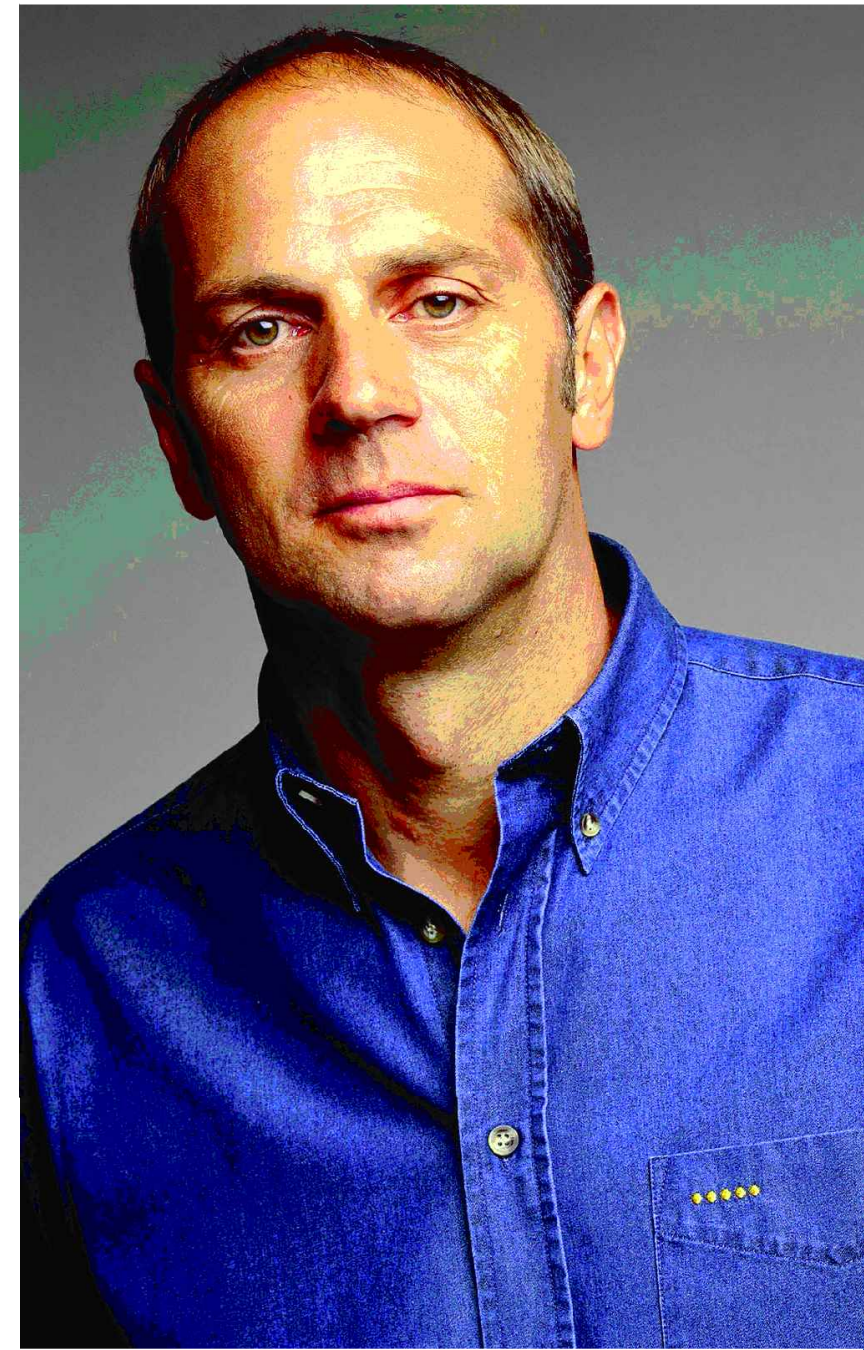

Sir Steven Redgrave

- quantity of fuel stored in the form of glycogen in the skeletal muscles

- capacity for gluconeogenesis and mobilisation of fat stores, and

- ability to tolerate raised levels of lactate.

\section{Blood glucose control}

In diabetes, several important variations in physiology are likely to influence mobilisation of fuels and control of blood glucose during exercise. Insulin is administered subcutaneously, where it lies in depots and takes time both to be absorbed and to disperse. Insulin concentrations following subcutaneous injection cause reversal of the physiological portal to systemic insulin ratio, which may be inappropriately high or low for concurrent glucose levels. ${ }^{22}$ Furthermore, the insulin levels required to regulate hepatic glucose output after subcutaneous injection may cause a supraphysiological peripheral concentration which impairs fuel mobilisation. The counter-regulatory hormone 
response to exercise, essential for gluconeogenesis and lipolysis, may be impaired in type 1 diabetes. ${ }^{23,24}$ The release of glucagon, the most important hormone in gluconeogenesis, is markedly reduced. Adrenaline and noradrenaline responses to exercise may also be reduced. These deficits in the counter-regulatory response limit the ability of the liver to support the increased muscle glucose uptake during exercise. The net effect of these changes is likely to produce a mismatch between glucose utilisation and production. ${ }^{25}$ Blood glucose levels therefore tend to fall during prolonged exercise rather than remain constant as in the non-diabetic state. During Steven's initial phase of training following diagnosis, hypoglycaemia became a serious problem as the periods of exercise increased in length and intensity.

Steven's observation of loss of power after five minutes at maximum exercise, confirmed by comparison with prediagnosis data, required specialist investigation. Physiological studies confirmed that glucose was the only significant fuel oxidised at maximum effort. There was no impairment of muscle glucose storage, his maximum glucose disposal during exercise exceeding $160 \mathrm{~g} /$ hour. ${ }^{26}$ Calculation of glucose utilisation and production demonstrated that approximately $25 \%$ of the energy required for intense exercise was derived from his liver. ${ }^{27}$ Impaired hepatic glucose production was thus the most important cause of his failing athletic performance after prolonged periods of exercise. Because most of the insulin-induced glucose disposal is into skeletal muscle, it was considered that hepatic glucose storage and release during exercise needed to be improved. To achieve this, he took extra glucose with additional doses of Lispro insulin to maximise glucose storage during rest periods immediately after exercise. ${ }^{28,29}$ This used the period of relative muscle insulin resistance during rest after exercise to optimise hepatic glucose storage, which in part balanced the abnormality in his physiology. Using this augmented feeding programme, Steven noticed an improvement in his power output, which then became close to his previous level of performance.

\section{Conclusion}

Winning gold medals in different rowing disciplines at five Olympic Games is a magnificent sporting achievement. But Steven's three years of intense physical and metabolic preparation following the diagnosis of diabetes, culminating in the Gold Medal he won at the 2000 Olympics in Sydney, Australia, speak for almost superhuman personal commitment and courage. This was not only a triumph for Steven and the expert support team, but sets an example to anyone with diabetes or other chronic diseases. With an understanding of how the body works in health and under stress, every individual can look to the stars and aim for gold.

\section{References}

1 Chatterjee S, Gallen IW, Sandler L. 2-year prospective audit of the effect of the introduction of insulin lispro in patients with specific clinical indications. Diabetes Care 1999;22:1226-7.

2 Jacobs MA, Keulen ET, Kanc K, Casteleijn S et al. Metabolic efficacy of preprandial administration of Lys(B28), Pro(B29) human insulin analog in IDDM patients. A comparison with human regular insulin during a three-meal test period. Diabetes Care 1997;20:1279-86.

3 Wilde MI, McTavish D. Insulin lispro: a review of its pharmacological properties and therapeutic use in the management of diabetes mellitus. Review. Drugs 1997;54:597-614.

4 Sonnenberg GE, Kemmer FW, Berger M. Exercise in type 1 (insulin-dependent) diabetic patients treated with continuous subcutaneous insulin infusion. Prevention of exercise induced hypoglycaemia. Diabetologia 1990;33:696-703.

5 Oskarsson PR, Lins PE, Wallberg Henriksson H, Adamson UC. Metabolic and hormonal responses to exercise in type 1 diabetic patients during continuous subcutaneous, as compared to continuous intraperitoneal, insulin infusion. Diabetes Metabol 1999;25:491-7.

6 Nugent AM, Steele IC, al-Modaris F, Vallely S et al. Exercise responses in patients with IDDM. Diabetes Care 1997;20:1814-21.

7 Veves A, Saouaf R, Donaghue VM, Mullooly CA et al. Aerobic exercise capacity remains normal despite impaired endothelial function in the micro- and macrocirculation of physically active IDDM patients. Diabetes 1997;46:1846-52.

8 Medbo JI, Tabata I. Relative importance of aerobic and anaerobic energy release during short-lasting exhausting bicycle exercise. J Appl Physiol 1989;67:1881-6.

9 Margaria RD, Oliva PE, Di Prampero D, Cerretelli P. Energy utilization in intermittent exercise of supramaximal intensity. J Appl Physiol 1969;26:752-6.

10 Hultman E, Sjöholm H. Energy metabolism and contraction force of skeletal muscle in situ during electrical stimulation. J Physiol 1983;345:525-32.

11 Jansson E, Hjemdahl P, Kaijser L. Epinephrine-induced changes in muscle carbohydrate metabolism during exercise in male subjects. J Appl Physiol 1986;60:1466-70.

12 Marliss EB, Simantirakis E, Miles PD, Purdon C et al. Glucoregulatory and hormonal responses to repeated bouts of intense exercise in normal male subjects. J Appl Physiol 1991;71:924-33.

13 Wolfe RR, Nadel ER, Shaw JH, Stephenson LA, Wolfe MH. Role of changes in insulin and glucagon in glucose homeostasis in exercise. J Clin Invest 1986;77:900-7.

14 Hirsch IB, Marker JC, Smith LJ, Spina RJ et al. Insulin and glucagon in prevention of hypoglycemia during exercise in humans. Am J Physiol 1991;260(5 Pt 1):E695-704.

15 Kjaer M, Engfred K, Fernandes A, Secher NH, Galbo H. Regulation of hepatic glucose production during exercise in humans: role of sympathoadrenergic activity. Am J Physiol 1993;265(2 Pt 1):E275-83.

16 Coker RH, Krishna MG, Lacy DB, Bracy DP, Wasserman DH. Role of hepatic alpha- and beta-adrenergic receptor stimulation on hepatic glucose production during heavy exercise. Am J Physiol 1997; 273(5 Pt 1):E831-8.

17 Marker JC, Hirsch IB, Smith LJ, Parvin CA et al. Catecholamines in prevention of hypoglycemia during exercise in humans. Am J Physiol 1991;260(5 Pt 1):E705-12.

18 Cryer PE. Glucose counterregulation: prevention and correction of hypoglycaemia in humans. Review. Am J Physiol 1993;264(2 Pt 1): E149-55.

19 Coggan AR, Raguso CA, Gastaldelli A, Williams BD, Wolfe RR. Regulation of glucose production during exercise at $80 \%$ of V02 peak in untrained humans. Am J Physiol 1997;273(2 Pt 1):E348-54.

20 Romijn JA, Coyle EF, Sidossis LS, Gastaldelli A et al. Regulation of endogenous fat and carbohydrate metabolism in relation to exercise intensity and duration. Am J Physiol 1993;265(3 Pt 1):E380-91.

21 Randle PJ, Newsholme EA, Garland PB. Regulation of glucose uptake by muscle. 8 . Effects of fatty acids, ketone bodies and pyruvate, and of alloxan-diabetes and starvation, on the uptake and metabolic fate of glucose in rat heart and diaphragm muscles. Biochem J 1964;93:652-5.

22 Wasserman DH, Abumrad NN. Physiological bases for the treatment of the physically active individual with diabetes. Review. Sports Med 1989;7:376-92. 
23 Ahlborg G, Lundberg JM. Exercise-induced changes in neuropeptide Y, noradrenaline and endothelin-1 levels in young people with type I diabetes. Clin Physiol 1996;16:645-55.

24 Koivisto VA, Sane T, Fyhrquist F, Pelkonen R. Fuel and fluid homeostasis during long-term exercise in healthy subjects and type I diabetic patients. Diabetes Care 1992;15:1736-41.

25 Berger M, Assal JP, Jorgens V. [Physical exercise in the diabetic. The importance of understanding endocrine and metabolic responses.] Review. French. Diabet Metab 1980;6:59-69.

26 Peirce NS. Centre for Sports Medicine, University Hospital, Nottingham, UK.

27 Howlett K, Febbraio M, Hargreaves M. Glucose production during strenuous exercise in humans: role of epinephrine. Am J Physiol 1999;276(6 Pt 1):E1130-5.

28 Tamis-Jortberg B, Downs DA Jr, Colten ME. Effects of a glucose polymer sports drink on blood glucose, insulin, and performance in subjects with diabetes. Diabetes Educ 1996;22:471-87.

29 McKewen MW, Rehrer NJ, Cox C, Mann J. Glycaemic control, muscle glycogen and exercise performance in IDDM athletes on diets of varying carbohydrate content. Int J Sports Med 1999;20:349-53. 